\title{
Diary Reports on Emotional Experiences in the Onset of a Psychosocial Transition: Becoming Drug-Free
}

\author{
MARCELLA RAVENNA, ${ }^{1}{ }^{*}$ ERIK HÖLZL ${ }^{2}$ SANDRO COSTARELLI, ${ }^{3}$ \\ ERICH KIRCHLER ${ }^{2}$ and AUGUSTO PALMONARI ${ }^{4}$ \\ ${ }^{1}$ Department of Human Sciences, University of Ferrara, Italy \\ ${ }^{2}$ Department of Psychology, University of Vienna, Austria \\ ${ }^{3}$ Department of Human and Social Sciences, University of Trento, Italy \\ ${ }^{4}$ Department of Sciences of Education, University of Bologna, Italy
}

\begin{abstract}
The process of becoming drug free is viewed as a psychosocial transition in the life of drug addicts. A specific form of treatment of heroin addiction within residential communities is based on the importance of interpersonal relationships for change. Well-being of 65 drug addicts during the first 2 weeks in a residential community is explored using a time-sampling diary which was completed four times a day. The influence of subjects' history, situational context, and motive activation on well-being and emotions is investigated. Results show that well-being and emotions differ mainly according to subjects' history, but not - at least at the beginning of treatment within the community - according to situations. This is interpreted as a 'state of shock' in the new environment and highlights the necessity for special individual care for subjects with a long drug career. Copyright (C) 2001 John Wiley \& Sons, Ltd.
\end{abstract}

Key words: drug addiction; drug-free; community treatment; emotional experiences

\section{INTRODUCTION}

Addiction to a drug like heroin ${ }^{1}$ represents the extreme phase of a long psychosocial process (Ravenna, 1993, 1995) often started with reference to the way in which drug addicts faced their specific adolescent developmental tasks (Palmonari, 1997). The changes in the experience of self that the individual undergoes if he becomes an addict recall the idea of 'moral career' (Goffman, 1961; Becker, 1953). An individual entering the world of heroin in fact elaborates a new self-representation and brings about new social identifications. As

\footnotetext{
*Correspondence to: Marcella Ravenna, Department of Human Sciences, University of Ferrara, via Savonarola 38, 44100-Ferrara, Italy. E-mail: rvm@dns.unife.it

${ }^{1}$ Addiction is defined by the World Health Organization (1964) as 'a psychic and sometimes even physical state, resulting from the interaction between organism and pharmacologically active substance, characterised by a certain type of behaviour and by other factors which often include a desire to consume the substance sporadically or continually, producing effects which act on the psyche and causing distress due to its absence'.
} 
soon as he realises he is addicted, he further redefines the way in which he considers himself and his own living environment. Moreover, being recognised by significant others as a drug addict considerably alters their reactions towards him (Ravenna et al., 1997). Just as drug addiction is the result of a long psychosocial process, overcoming addiction also represents an important transition in life in which the crucial task is to redefine the image of oneself (from that of drug-user to a person able to live without resorting to drugs) and relations with significant others (Biernacki, 1986; Prochaska and Di Clemente, 1996). Although addiction may sometimes be overcome spontaneously (Waldorf, 1983; O'Doherty and Davies, 1987), in most cases it requires forms of assisted treatment. Both these forms of remission imply a process of change which can be usefully analysed in agreement with the model of transition recently put forward by Ruble and Seidman (1996). The initial stage of a transition is seen as the point of intersection between the variables which operate in the previous state (or background experiences) and the initial experience of the disturbances associated with the transition. In other words, the drug history of the subject (precocity of initiation, duration of drug consumption, extent of associated dysfunctional experiences), type and intensity of the individual's link with the environment of drug consumption, the social network available to him while he is in treatment and how attracted he is by the idea of reactivating his capabilities of development (Ravenna and Zani, 1996) are all background elements which influence the way he interprets the event which starts off the transition (the decision to enter a treatment community) and which together with others (specific nature of the event, aspects relative to the context) influence the emotional reactions prior to the transition itself.

A widely used form of treatment in the field of drug addiction, both in Italy and in other countries, is represented by residential Communities (mostly private but also public). The general concept behind them is development. Change, mainly intended in terms of maturing and personal growth, has its goal in an 'adult' person being able to cope with inner states of discomfort and the occurrences of everyday life, to express his potential, to get a job, to establish and maintain affective ties, and to achieve conditions of sufficient psychological well-being without the help of drugs (Cagossi, 1988; Ravenna, 1991, 1997).

In the varied panorama of Italian Communities ${ }^{2}$, two different models of treatment can be found.

(a) The first, currently more widespread and well-known, takes its inspiration from the experience of Alcoholics Anonymous groups (1955), from the behavioural approach traditionally used in American concept-based communities (Kennard, 1983) and from the cognitive-behaviouristic approach (Miller, 1983; van Bilsen and van Emst, 1990; Monti et al., 1989). The change is based on learning processes (imitation of functional role models, mechanisms of reinforcement, feedback given by significant others), on problem solving and on the use of suitable procedures for modifying dysfunctional forms of thought. The treatment is aimed above all at altering the drug addict's conduct or lifestyle, strengthening specific aspects of his personality, or redefining it on a new basis (Ravenna, 1995).

(b) The second model, in the minority and not as well-known as the former, refers instead to the principle of leaving-learning which inspired the work of Maxwell Jones, to the contribution made by scholars of different orientation on the theme of change in adults

\footnotetext{
${ }^{2}$ There are 823 social residential rehabilitation structures in Italy mainly distributed in the northern and central regions (Ministero dell'interno, 1996).
} 
but particularly that which can be found in the studies carried out by Bettelheim (1960) on autistic children and by Redl and Wineman (1951) on strongly maladjusted preadolescent teenagers which underlines the role the environment can play in favouring experiences of recovery. The main idea is that any personal change can only come about in the framework of a deep interpersonal relationship and intense affective ties with significant people. The individual involved in such a process feels as if he has 'changed world', that he is subject to a deep transformation in which elements which were once extremely prominent lose their importance, whilst others thought to be of little value are emphasised (Gendlin, 1964; Berger and Luckman, 1966). The treatment aims to foster higher levels of self-awareness and contact with reality, a revision of relationships with significant others and the redefinition of the system of reference values (Finazzi, 1996). The main idea is that the change can only be fulfilled constructively if the teenager can rely on a structure of plausibility, or rather, a social basis (the significant people with whom he has a particularly intense emotional relationship) which acts as a laboratory for the transformation (Finazzi, 1996).

The therapeutic Communities in which our study was carried out are inspired by the latter model. They are small in size (taking a maximum of 10-30 guests) and have a 2-year rehabilitation programme. Guests enter of their own free will and are considered as individuals. As a result, the application of the rules is modulated according to their characteristics and to specific situations. The relationship between the staff (mostly professional educators) and guests allows for an involving direct mutual relationship, open to contact with outsiders. Daily life is regulated by an activity programme known to the guests, which also provides for time dedicated to personal initiative. During the day the guests are kept busy with paid working activities which are appropriate for individual psychological and physical possibilities. Periodically, they take part in group self-help sessions in which the difficulties encountered in daily life are discussed and in others restricted to the participants in a specific phase of the programme. The remaining time is used for communal meals, and in free activities which are both collectively and individually managed.

\section{RESEARCH OBJECTIVES}

This study, which constitutes the first part of a wider longitudinal research, examines the mood and its determinants of a small sample of drug addicts during the first 2 weeks at a therapeutic Community of a non-behaviouristic orientation. In agreement with the definition of 'present' well-being (Becker, 1991), mood is understood here as the momentary state experienced by the individual (in an interval of time which ranges from a few seconds to an hour), differentiated according to intrinsic characteristics of intensity and value.

We considered it useful to study the mood of these subjects both because it reflects their general state at a given moment (Jacobsen, 1957; Nowlis and Nowlis, 1956), and particularly because it is an important source of information about the situation that they themselves are experiencing in terms of feelings of trust vs. threat (Clore, 1992) that influence their judgements, the way in which they process information and work through their selfconcept. These are all elements which in turn influence the way in which the beginning of transition is faced, in other words the very first stage of life in the Community (Ruble and Seidman, 1996). 
The first question we asked ourselves was the following in particular: 'What is the mood of the subjects during their first days in the Community?' Since entrance into treatment coincides with the start of the transition (Ruble and Seidman, 1996) and is characterised by a radical change in the living environment and in the personal habits of the subjects involved, we expect them to experience high levels of disturbance which are expressed in moods of negative orientation. This expectation is indirectly supported by the results of previous cross-sectional research (Ravenna et al., 1997; Ravenna and Zani, 1996) which has included drug addicts in different stages of residential and non-residential treatment and which show that the initial stage is associated with particularly dysfunctional self-representations, intense feelings of worry, lack of confidence in relation to the future and resorting to non-adaptive coping strategies.

We also asked ourselves how much the moods experienced by the subjects on their entrance into the Community differed in relation to certain background experiences regarding their drug history. As regards the duration of drug addiction we know that the longer the period of addiction, the more it may have disturbed the processes of transition from the adolescent phase to the youth-adult phase (Carman, 1979; Baumrind and Moselle, 1985). The focussing on the substance, reducing the level of articulation and differentiation of the living space of the subject (as regards activity, interests, projects, social exchanges) may have 'frozen' the adolescent process and promoted a definition of the self at a fairly primitive level comparable with that of the diffused self (Breckler and Greenwald, 1986; Ravenna and Kirchler, 2000). In addition, the cross-sectional research mentioned above shows that an early start in using heroin and a long-term drug addiction are associated with more negative representations of the self. These considerations lead us to presume that, by questioning consolidated forms of personal equilibrium, the interruption of consolidated habits of consumption, coinciding with entrance into the Community, could produce strong feelings of personal distress and discontinuity able to favour negative emotional states.

As regards possible previous failures in the treatment, our expectations are not so univocal. Evidence found in literature suggests that failures reduce the feelings of effectiveness and personal control, increasing those feelings of failure (which can in turn be associated with those feelings of failure which brought about the encounter with heroin; Alexander, 1990; Alexander and Hadaway, 1982), though it could also suggest that they can instead stimulate the subject to adopt strategies other than those previously used and make a greater effort to achieve abstention (Prochaska and Di Clemente, 1986). Besides these considerations, we should also add that those who have already had experience of treatment are more familiar with the context and may have fewer problems of initial adaptation to the Community because of the fact that they know the rules of the game.

As regards possible problems with the law, we may presume that those who have been to prison have had more frequent contact with the world of illegality, higher levels of involvement in illegal activities and have been labelled not only as a drug addict but also as a deviant and that all this may have produced more or less intense feelings of discontinuity in the self experience. However it should also be borne in mind that those who have been to prison may experience the entrance into a Community with a certain relief if they identify it as a less rigid and more human context, or with feelings of oppression if instead they consider it in continuity with previous experiences of restriction of personal liberty.

Finally, we asked ourselves to what extent the moods of the subjects on entrance to the Community differed according to certain characteristics of the context. Since the model of therapy applied in the Communities considered in this study (Finazzi, 1996) involves a 
variegated range of experiences and interpersonal interactions, it may be presumed that the mood of the subjects passes through alternating phases. They face the various situations of daily life in the Community with the motivation to satisfy specific needs (power, affiliation, success, etc.) which instead are sometimes frustrated. Satisfaction and frustration of needs are reflected on their emotional experiences, in the final analysis determining the overall mood relative to the new experience of life in progress.

We felt it was important to consider the context in differentiated terms because in this way it is possible to discern the variation of the mood in relation to its different characteristics at a given moment (involvement in social activities vs. non-social activities, focussed vs. not focussed on the task).

In line with the proposals emerging from previous research (cf. Ravenna et al., 1997; Ravenna and Zani, 1996), the main point of innovation of this work lies in the monitoring of the mood of the drug addicts undergoing treatment at a therapy Community over a defined period of time, through the means of a diary. Now used in a number of research contexts (Brandstätter, 1977; Hormuth, 1986; Kirchler, 1983; Lewinson and Libet, 1972; Singer and Colligian, 1987), the time sampling diary has certain advantages with respect to the traditional mood scales, since it enables monitoring both of the subjective dimension (attributions, needs, etc.) as well as the situational (objective) dimension (place, activities completed, persons present, topics of dialogue, etc.) of the mood (Kirchler, 1984).

\section{METHOD}

\section{Sample}

Data has been obtained from drug addicts who started a 2-year long rehabilitation programme at one of the 10 residential treatment community centres belonging to the Italian 'PLOCRS' circuit. In all these communities, new clients who arrived between October 1997 and June 1998 were approached and asked to participate in the research; not a single person refused. The sample consisted of 74 participants: 56 men and 18 women. Age ranged from 20 to 41, with a mean of 29.14 years. The majority had only compulsory schooling. Participants were also asked about drug-related issues and legal problems. A total of 38 participants had been in prison themselves, 22 were registered with the authorities, and 14 had no legal problems. Thirty-one participants reported previous stays in other therapeutic communities. Participants reported an average of 9.70 years of heroin taking, ranging from 1 to 22 years. They also were asked how old they were when starting abuse of several substances. These reports were collated for legitimate drugs (alcohol, nicotine, tranquillisers and sleeping tablets), non-legitimate light (hashish, marijuana, poppers, glue) and non-legitimate heavy drugs (ecstasy, LSD, amphetamines, cocaine, heroin) by using the minimum reported age within each class. Participants reported having started using legitimate drugs at an age of 13.58, non-legitimate light drugs at 15.65 , and heavy drugs at an age of 17.95. Details are given in Table 1.

\section{Material and procedure}

On the first day of staying at the respective rehabilitation centre, each participant was informed about the goal of the study and the procedure by the head of the centre. Handling of the diary sheets was explained to the participants by filling out some fictitious diary sheets with assistance of the head of the centre. Participants completed a questionnaire 
Table 1. Sample and cluster description

\begin{tabular}{|c|c|c|c|c|}
\hline & $\begin{array}{c}\text { Total } \\
n=74 \\
\end{array}$ & $\begin{array}{c}\text { Cluster } 1 \\
n=24\end{array}$ & $\begin{array}{c}\text { Cluster } 2 \\
n=16\end{array}$ & $\begin{array}{c}\text { Cluster } 3 \\
n=25\end{array}$ \\
\hline Age in years $(M, \mathrm{SD})$ & $29.14(5.16)$ & $30.08(5.39)$ & $28.87(5.13)$ & $28.00(4.66)$ \\
\hline Gender $(f) \quad$ female & 18 & 8 & 3 & 4 \\
\hline male & 56 & 16 & 13 & 21 \\
\hline Education $(f)$ elementary school & 11 & 1 & 6 & 3 \\
\hline compulsory school & 54 & 20 & 10 & 17 \\
\hline high school & 9 & 3 & 0 & 5 \\
\hline Occupational status $(f)$ unemployed & 24 & 9 & 7 & 4 \\
\hline employed & 50 & 15 & 9 & 21 \\
\hline Legal problems $(f) \quad$ arrest & 38 & 16 & 16 & 2 \\
\hline registration & 22 & 7 & 0 & 12 \\
\hline no legal problems & 14 & 1 & 0 & 11 \\
\hline Years of taking heroin $(M, \mathrm{SD})$ & $9.70(4.98)$ & $11.88(5.35)$ & $10.56(4.68)$ & $8.08(3.83)$ \\
\hline Age when first taking drugs & & & & \\
\hline legitimate drugs $(M, \mathrm{SD})$ & $13.58(2.91)$ & $13.04(1.81)$ & $12.31(3.07)$ & $14.29(2.26)$ \\
\hline non-legitimate, light drugs $(M, \mathrm{SD})$ & $15.65(2.47)$ & $14.86(1.42)$ & $15.07(2.22)$ & $16.04(2.03)$ \\
\hline non-legitimate, heavy drugs $(M, \mathrm{SD})$ & $17.95(3.47)$ & $17.13(2.21)$ & $16.81(2.51)$ & $18.80(3.93)$ \\
\hline Previous stay in other & 31 & 24 & 1 & 1 \\
\hline therapeutic communities $(f)$ no & 43 & 0 & 15 & 24 \\
\hline
\end{tabular}

Frequency $(f)$, mean $(M)$, standard deviation (SD). Columns 2, 3 and 4 describe the 65 subjects who completed the diary. 
concerning demographic data, education, work experience, family of origin, partner, drug history, legal history, prostitution, previous treatments and health. Furthermore, self-image was assessed by the procedure reported by Ravenna et al. (1997).

The diary was a time-sampling mood diary, similar to the one designed by Brandstätter (1977). During each of the first 14 days of the rehabilitation programme, the participants had to answer several items on the diary sheet at four points in time between 7 am and $11 \mathrm{pm}$. The recording times had been randomly selected by the researchers for each day of the study and for each participant, and were indicated in a calendar which was given to each participant on the first day. Completion of the diary sheet took about 1 to 2 minutes. After completion, each participant had to put the diary sheet into a diary-safe, consisting of a paper box with a small slot for the sheets. All diary-safes were collected daily by the centre's head directly from the participant and mailed to the researchers after the fourteenth day. In order to guarantee complete anonymity of his/her registrations, each participant had been instructed to choose and put a personal code on each diary.

At each registration session the participants had to record their personal code, date and time and answer several items.

(1) Situational characteristics: participants were asked about (a) place, (b) present activity, (c) other persons present and (d) topic of the conversation, if any.

(2) Mood: participants were asked whether they felt (a) good or bad, (b) strong or weak and (c) free or restricted in the choice of their actions on a five-point Likert scale.

(3) Emotions: participants had to report their feelings by ticking one or more emotions in a circle containing the list of emotions by Plutchik (1980).

(4) Time perspective of overall mood and emotional state, i.e. whether it derived from past, present, or future events.

(5) Attributions: participants were asked about the source(s) of their overall mood and emotional state.

(6) Motives: participants had to report up to three motives from a list of 18 motives (Brandstätter, 1983) that were satisfied or frustrated at the moment and responsible for their current positive or negative mood, respectively.

After completing the last diary sheet on the fourteenth day, each participant was asked to complete a short follow-up questionnaire. Participants were asked how difficult they found the diary, whether they had reported honestly and reliably, and how often they had not filled in the diary on time.

\section{RESULTS}

\section{Overview}

As the first step, data quality is explored and the analysis of diary data explained. To allow for analysis of person-situation interactions, the next step is the clustering of participants and the grouping of situations. Throughout the analysis, two questions are prevalent: (a) how often a certain combination of factors occurs (relative frequencies) and (b) how the participants feel in these cases (well-being). First, the quality of experience is explored by analysing emotions by clusters and settings. Then the focus is on well-being, which is first analysed as dependent from cluster and setting. In further steps, the antecedents of wellbeing are explored. Is well-being different when certain motives are activated? 
Data quality. Diary data was provided by 65 participants with a total of 3350 reports; diaries from nine subjects were not usable. The number of reports per subject varied between a minimum of 21 and the theoretical maximum of 56 reports. Thirty-one subjects supplied 56 reports each; the average number of reports per subject amounts to 51.54. Most diary sheets were completed well. On 2791 of the 3350 sheets, all items were answered (83\%). On 379 sheets, only one item was omitted (11\%), on 180 sheets between two and four items were missing (5\%). Fifty-two participants answered the follow-up questionnaire. They reported that the diary was rather easy to complete $(M=5.38$, $\mathrm{SD}=1.44)$. Participants said that they had reported honestly $(M=5.69, \mathrm{SD}=1.09)$ and reliably $(M=5.94, \mathrm{SD}=0.96$, seven-point scales each). When asked how often they did not fill in the diary exactly on time, they reported an average of five occasions, corresponding to approximately $10 \%$ of reports. These results indicate a rather good overall data quality for subsequent analyses.

Analysis. Data analysis on an event level would have led to severe shortcomings when using conventional analysis methods due to an inflation of degrees of freedom. In order to explore individual-situation interactions, data was aggregated within settings, and those aggregated values were the primary unit of analysis. For analyses of relative frequencies, the number of occurrences was divided by the number of individual reports within a certain setting; if the event of interest was not reported, a frequency of zero was assigned. For analyses of well-being, individual well-being within a setting was averaged. For each person therefore the number of observations was reduced from a maximum of 56 into a maximum of 12 , one aggregated value per setting. Since motive classes were not mentioned in every setting, the number of observations is reduced. For the analysis of well-being as dependent from motive class, a minimum cell frequency of five observations was used; settings that did not match this criterion were excluded.

Clusters of individuals. Participants were clustered according to their drug-related characteristics: (a) number of years taking heroin, (b) minimum age at first taking legitimate, (c) illegitimate light and (d) illegitimate heavy drugs, respectively, (e) legal problems (recorded into having been arrested vs. not) and (f) previous stays in other therapeutic communities. A cluster analysis with these standardised variables using the Ward method suggested three clusters with 27, 18 and 29 participants. Post hoc tests following an analysis of variance showed that cluster 1 and cluster 2 differ mainly in prison experience and experience with other communities, but not in age when starting drugs abuse or years taking heroin. While all members of cluster 1 have been to other therapeutic communities, only one member of cluster 2 had. All members of cluster 2 have been arrested before, while only 17 of cluster 1 have. Cluster 3 differs from cluster 1 and 2 in years taking heroin as well as in starting ages: they started drug usage later, and show less years of heroin taking. Only three persons in this group have been arrested, and only three have experience with other communities. A multivariate analysis of variance showed no significant difference between clusters concerning other sociodemographic variables $(F<1)$. Since only 65 participants completed the diary, the number of participants in each cluster decreases: cluster 1 consists of 24 participants, cluster 2 of 16, and cluster 3 of 25 participants. Their full sociodemographic characteristics are given in Table 1.

Situational settings. Situational variables in the diary concerned places (session rooms, private rooms, elsewhere in the centre, outside the centre), activities (leisure, work, 
therapy), and social interaction (being alone, with other participants, with practitioners, or with other persons). Since not all combinations of places, activities, and social contacts occur within the community, 12 settings were constructed to tap the most frequent situations. Table 2 gives an overview of these settings. Only 44 of the 3350 reports did not fit into these 12 settings and were excluded from further analyses.

\section{Emotions}

The most frequently recorded emotion was optimism with 1461 reports. Anticipation (901), acceptance (869) and joy (809) are very frequently mentioned emotions, followed by sadness (433) and love (405), surprise (205), disappointment (207) and remorse (171). These emotions are mentioned by at least 40 persons. Quite rare, and also mentioned by fewer persons, are aggressiveness (152), submission (145), fear (129) and anger (126). Very rare, and mentioned by less than 25 participants, are reports of awe (67), disgust (66), and contempt (57). For each person and setting, the absolute frequency of reporting a specific emotion was calculated and divided by the number of reports within this setting. Relative frequencies averaged over settings and clusters are given in Table 3.

A 3 (cluster) $\times 12$ (setting) multivariate analysis of variance with the relative frequencies of the 16 emotions as dependent variables showed a multivariate effect of cluster $(F(32,986)=4.04, p<0.001)$, but no other effects $(F \leq 1)$. Univariate $F$-tests showed significant differences in joy, surprise, disgust, anger, anticipation, optimism, love, remorse, and aggressiveness. Participants belonging to cluster 3 report joy, optimism, love, and aggressiveness more often, and anticipation less often than the other two groups. Cluster 2 mentions disgust more often than individuals belonging to the other two groups, and surprise less often. Cluster 1 mentions anger and remorse less frequently than the other groups.

Table 2. Situational settings

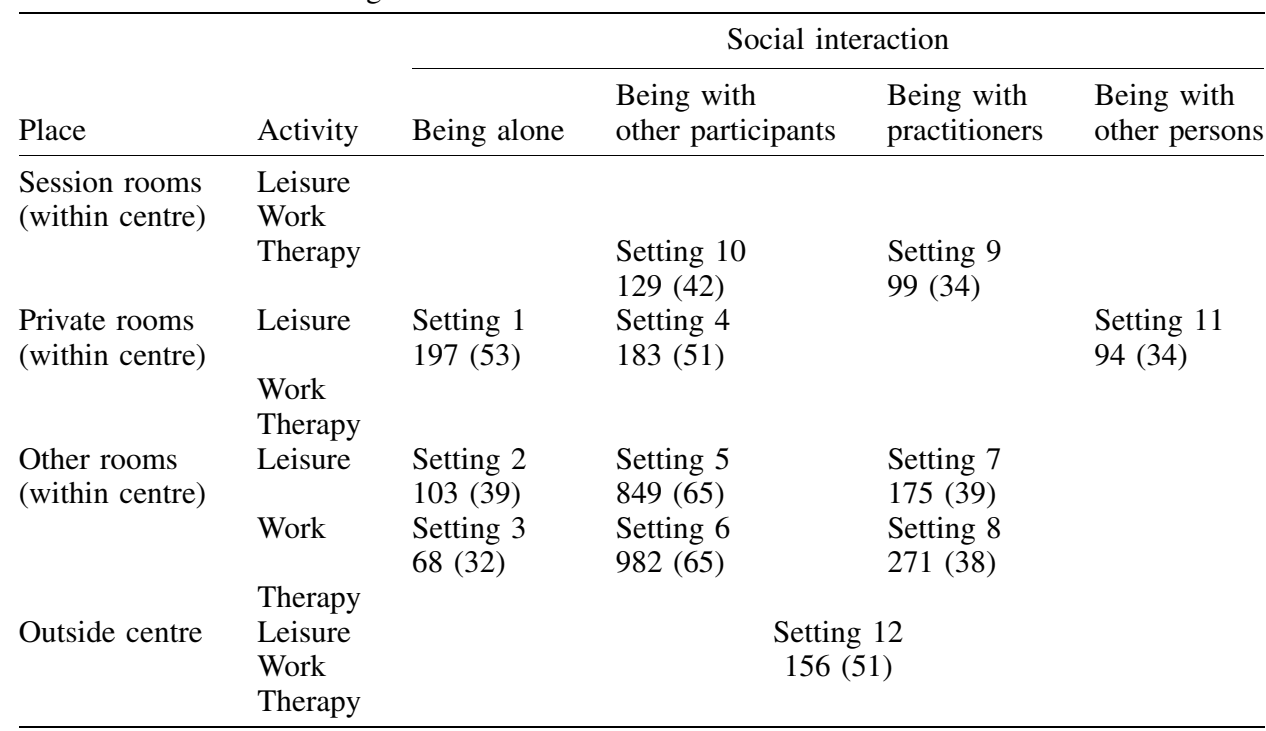

Number of reports in setting; number of persons reporting on setting in parentheses. 
Table 3. Emotions by cluster

\begin{tabular}{|c|c|c|c|c|c|c|c|c|c|}
\hline \multirow{3}{*}{ Acceptance } & \multirow{3}{*}{$\begin{array}{l}M(\mathrm{SD}) \\
f\left(n_{p}\right)\end{array}$} & \multicolumn{2}{|c|}{ Cluster 1} & \multicolumn{2}{|c|}{ Cluster 2} & \multicolumn{2}{|c|}{ Cluster 3} & \multicolumn{2}{|c|}{ Total } \\
\hline & & 0.26 & $(0.35)$ & 0.25 & $(0.33)$ & 0.23 & $(0.30)$ & 0.24 & (1) 33 \\
\hline & & 350 & (22) & 189 & (12) & 330 & (22) & 869 & (56) \\
\hline \multirow[t]{2}{*}{ Submission } & $M(\mathrm{SD})$ & 0.04 & $(0.15)$ & 0.05 & $(0.15)$ & 0.03 & $(0.12)$ & 0.04 & $(0.1$ \\
\hline & $f(n$ & 47 & (10) & 59 & (8) & 39 & (14) & 145 & (32) \\
\hline \multirow[t]{2}{*}{ Fear } & SD) & 0.04 & $(0.14)$ & 0.07 & (0.19) & 0.06 & $(0.18)$ & 0.05 & $(0.17$ \\
\hline & $f\left(n_{p}\right)$ & 36 & (11) & 41 & (10) & 52 & (12) & 129 & (33) \\
\hline \multirow[t]{2}{*}{ Awe } & $M(\mathrm{SD})$ & 0.02 & $(0.10)$ & 0.03 & $(0.13)$ & 0.03 & $(0.11)$ & 0.03 & $(0$. \\
\hline & $f\left(n_{p}\right)$ & 15 & (8) & 14 & (5) & 38 & (9) & 67 & (22) \\
\hline \multirow[t]{2}{*}{ Surprise } & & 0.07 & $(0$. & 0.03 & $(0$. & 0.09 & & 0.07 & $(0.1$ \\
\hline & & 64 & (15) & 33 & (8) & 108 & (20) & 205 & (43) \\
\hline \multirow[t]{2}{*}{ Disappointment } & & 0.07 & $(0$. & 0.09 & $(0.2$ & 0.07 & $(0.1$ & 0.08 & 1 \\
\hline & $f(n$ & 73 & (18) & 52 & (9) & 82 & (18) & 207 & (45) \\
\hline \multirow[t]{2}{*}{ Sadness } & $M(\mathrm{SD})$ & 0.14 & $(0.25)$ & 0.17 & $(0.28)$ & 0.14 & $(0.27)$ & 0.14 & $(0.2$ \\
\hline & $f\left(n_{p}\right)$ & 154 & (23) & 102 & (14) & 177 & (23) & 433 & $(60)$ \\
\hline \multirow[t]{2}{*}{ Remorse } & & 0.03 & $(0$. & 0.08 & $(0.1$ & 0.07 & $(0.1$ & 0.06 & $(0.1$ \\
\hline & & 31 & (11) & 53 & (13) & 87 & (17) & 171 & (41) \\
\hline \multirow[t]{2}{*}{ Disgust } & & 0.02 & (0. & 0.06 & $(0.1$ & 0.01 & $(0.0$ & 0.03 & $(0.1$ \\
\hline & $f(n$ & 17 & (6) & 29 & (7) & 20 & (4) & 66 & (17) \\
\hline \multirow[t]{2}{*}{ Contempt } & $M(\mathrm{SD})$ & 0.01 & $(0.05)$ & 0.03 & $(0.12)$ & 0.02 & $(0.09)$ & 0.02 & $(0.0$ \\
\hline & & 14 & (7) & 10 & (4) & 33 & (10) & 57 & (21) \\
\hline \multirow[t]{2}{*}{ Anger } & & 0.02 & $(0.0$ & 0.05 & $(0.1$ & 0.05 & $(0.14)$ & 0.04 & $(0.1$ \\
\hline & $f($ & 24 & (11) & 33 & (9) & 69 & (10) & 126 & (30) \\
\hline \multirow{2}{*}{ Aggressiveness } & & 0.01 & $(0.0$ & 0.03 & $(0.10)$ & 0.07 & $(0.18)$ & 0.04 & $(0.1$ \\
\hline & $f\left(n_{p}\right)$ & 25 & (12) & 23 & (11) & 104 & (15) & 152 & (38) \\
\hline \multirow[t]{2}{*}{ Anticipation } & $M(\mathrm{SD})$ & 0.30 & $(0.35)$ & 0.29 & $(0.38)$ & 0.20 & $(0.29)$ & 0.26 & $(0.3$ \\
\hline & $f\left(n_{p}\right)$ & 370 & (21) & 253 & (15) & 278 & (23) & 901 & (59) \\
\hline \multirow[t]{2}{*}{ Optimism } & & 0.39 & $(0.38)$ & 0.34 & $(0.38)$ & 0.48 & $(0.40)$ & 0.42 & $(0.3$ \\
\hline & $f\left(n_{t}\right.$ & 503 & (20) & 298 & (15) & 660 & (24) & 1461 & (59) \\
\hline \multirow{2}{*}{ Joy } & $M(\mathrm{SD})$ & 0.18 & $(0.27)$ & 0.20 & $(0.31)$ & 0.36 & $(0.38)$ & 0.26 & $(0.3$ \\
\hline & $f\left(n_{p}\right)$ & 206 & (22) & 160 & (13) & 443 & (23) & 809 & (58) \\
\hline \multirow[t]{2}{*}{ Love } & $M(\mathrm{SD})$ & 0.10 & $(0.25)$ & 0.10 & $(0.24)$ & 0.17 & $(0.31)$ & 0.13 & $(0.2$ \\
\hline & $f\left(n_{p}\right)$ & 111 & (14) & 66 & (8) & 228 & (18) & 405 & (40) \\
\hline
\end{tabular}

Mean $(M)$, standard deviation (SD) of relative frequencies. Total frequency $(f)$ of reports of emotion and number of persons reporting $\left(n_{p}\right)$.

\section{Well-being by cluster and setting}

In each situation, subjects reported whether they felt good or bad, strong or weak, and free or restricted in their actions on a five-point scale. Overall, the 65 subjects reported feeling moderately good $(M=3.53, \mathrm{SD}=0.73)$, strong $(M=3.37, \mathrm{SD}=0.78)$ and free $(M=3.25$, $\mathrm{SD}=0.81)$. Well-being was furthermore assessed via motive activation. Reporting motive satisfaction was coded as 1 , motive frustration as -1 , and both motive satisfaction and frustration as 0 . Participants mainly report motive satisfaction $(M=0.43, \mathrm{SD}=0.54)$. A factor analysis of these four measures yielded only one factor explaining $68 \%$ of variance. Factor scores were used for further analysis as the index of well-being, yielding a standardised well-being index. A value of zero reflects average well-being.

A 3 (cluster) $\times 12$ (setting) analysis of variance of this well-being index showed a significant effect of cluster $(F(2,507)=15.37 ; p<0.001)$, but no effect of setting $(F(11$, $507)=1.65 ; p=0.08)$ or interaction effect $(F(22,507)=0.85)$. Post hoc tests showed that all groups differ significantly: cluster 2 reports lowest well-being $(M=-0.31)$, cluster 1 
average well-being $(M=-0.10)$, and cluster 3 highest well-being $(M=0.20)$. Results are given in Table 4.

\section{Well-being by motives}

In 3238 diary sheets at least one of the 18 positively or negatively worded motives is mentioned. On 807 occasions, only negative motives were reported; on 2303 occasions only positive motives were reported, 171 times positive and negative motives were mentioned. First, motives were grouped according to Brandstätter (1983) into six motive classes: (a) physical comfort (physical comfort); (b) power (autonomy, prestige, power, self-esteem, self-assertiveness, revenge); (c) affiliation (affiliation, nurturance, love, sex); (d) sentience (activity, experience); (e) achievement and (f) higher order motives (order, understanding, aesthetic and ethical values). Since multiple responses and ambivalent feelings were possible, the total number of motives mentioned exceeds the total number of reports. Values for relative frequency and well-being averaged over settings are shown in Table 5.

An analysis of variance with motive class within subjects as independant variable and with relative frequency of motive activation as dependent variable showed a significant

Table 4. Well-being by cluster and setting

\begin{tabular}{lccrrrrrr}
\hline & \multicolumn{2}{c}{ Cluster 1 } & \multicolumn{2}{c}{ Cluster 2} & \multicolumn{2}{c}{ Cluster 3 } & \multicolumn{2}{c}{ Total } \\
Setting & $M$ & $(\mathrm{SD})$ & \multicolumn{1}{c}{$M$} & $(\mathrm{SD})$ & \multicolumn{1}{c}{$M$} & \multicolumn{1}{c}{ (SD) } & \multicolumn{1}{c}{$M$} & $(\mathrm{SD})$ \\
\hline 1 & -0.32 & $(1.01)$ & -0.29 & $(1.05)$ & 0.13 & $(1.05)$ & -0.13 & $(1.04)$ \\
2 & -0.13 & $(0.81)$ & -0.09 & $(1.08)$ & -0.04 & $(1.13)$ & -0.09 & $(0.96)$ \\
3 & -0.17 & $(0.92)$ & -10.27 & $(0.58)$ & 0.34 & $(0.89)$ & -0.15 & $(1.00)$ \\
4 & -0.04 & $(0.99)$ & -0.54 & $(0.83)$ & 0.11 & $(0.97)$ & -0.09 & $(0.96)$ \\
5 & -0.01 & $(0.68)$ & -0.01 & $(0.77)$ & 0.20 & $(0.88)$ & 0.07 & $(0.78)$ \\
6 & -0.17 & $(0.55)$ & -0.29 & $(0.77)$ & 0.17 & $(0.78)$ & -0.07 & $(0.72)$ \\
7 & -0.06 & $(0.98)$ & 0.10 & $(1.04)$ & 0.19 & $(1.05)$ & 0.07 & $(1.00)$ \\
8 & -0.05 & $(0.62)$ & -0.50 & $(1.03)$ & 0.25 & $(0.72)$ & -0.03 & $(0.81)$ \\
9 & -0.33 & $(0.91)$ & -0.96 & $(0.64)$ & 0.05 & $(0.87)$ & -0.30 & $(0.91)$ \\
10 & 0.01 & $(0.95)$ & -0.32 & $(0.72)$ & -0.02 & $(0.84)$ & -0.10 & $(0.83)$ \\
11 & 0.45 & $(0.68)$ & -0.33 & $(0.73)$ & 0.49 & $(0.67)$ & 0.31 & $(0.74)$ \\
12 & -0.11 & $(1.00)$ & 0.12 & $(0.65)$ & 0.50 & $(0.67)$ & 0.19 & $(0.84)$ \\
Total & -0.10 & $(0.84)$ & -0.31 & $(0.86)$ & 0.20 & $(0.88)$ & -0.02 & $(0.88)$ \\
\hline
\end{tabular}

Mean $(M)$, standard deviation (SD). Setting descriptions are given in Table 2.

Table 5. Relative frequency of motive activation and respective well-being

\begin{tabular}{|c|c|c|c|c|c|c|}
\hline & \multicolumn{2}{|c|}{ Relative frequency } & \multicolumn{2}{|c|}{ Well-being } & \multirow[b]{2}{*}{$f$} & \multirow[b]{2}{*}{$\left(n_{p}\right)$} \\
\hline & $M$ & $(\mathrm{SD})$ & $M$ & $(\mathrm{SD})$ & & \\
\hline Physical comfort motives & 0.19 & $(0.22)$ & -0.15 & $(0.83)$ & 585 & $(57)$ \\
\hline Power motives & 0.48 & $(0.26)$ & -0.18 & $(0.78)$ & 1603 & $(6$ \\
\hline Affiliation motives & 0.41 & $(0.25)$ & 0.00 & $(0.76)$ & 1408 & $(6$ \\
\hline Sentience motives & 0.65 & $(0.22)$ & -0.08 & $(0.79)$ & 2122 & $(6$ \\
\hline Achievement motives & 0.15 & $(0.15)$ & 0.18 & $(0.71)$ & 609 & (60) \\
\hline Higher order motives & 0.47 & $(0.24)$ & 0.15 & $(0.64)$ & 1584 & (64) \\
\hline
\end{tabular}

Mean (M), standard deviation (SD), frequency of reports $(f)$ and number of persons reporting $\left(n_{p}\right)$. Relative frequency based on number of reports per setting and averaged over settings. 
effect of motive class $(F(5,320)=42.14, p<0.001)$. Post hoc tests showed that physical comfort and achievement $(M=0.19$ and $M=0.15$, respectively) are significantly less frequent than other motive classes. Sentience motives are significantly more frequent than all other motives $(M=0.65)$. Higher order motives, affiliation and power motives are in the medium range $(M=0.41-0.48)$. Fifty-four subjects reported on all six motive classes (20 from cluster 1, 15 from cluster 2 and 19 from cluster 3); their data was used in a 6 (motive class, within-subjects) analysis of variance of well-being. Because data in Table 5 is based on all respondents, and the following analysis is confined to those 54 subjects who reported all six motive classes, slight differences between values in Table 5 and those reported later can occur. The analysis showed a significant effect of motive class $(F(5,265)=9.75$, $p<0.001)$. Post hoc tests showed that when achievement motives or higher order motives are activated, well-being is significantly better ( $M=0.15$ and $M=0.07$, respectively) than in the other four motive classes. When power motives are activated, well-being is significantly worse $(M=-0.24)$ than when affiliation or sentience motives are activated ( $M=-0.06$ and $M=-0.13$, respectively), and slightly worse than when physical comfort motives are activated $(M=-0.15)$.

Since a multivariate analysis with cluster, setting and motive class was not possible because of small cell frequencies, each motive class was analysed separately. Both relative frequencies and well-being were analysed by 3 (cluster) $\times 12$ (settings) analyses of variance. Settings were excluded if less than five participants of each cluster reported on them.

Relative frequency. For physical comfort motives, a significant cluster effect exists $(F(2,507)=6.65, p<0.01)$. This motive class is mentioned more frequently by cluster $1(M=0.19)$ and cluster $2(M=0.24)$ than by cluster $3(M=0.13)$. For affiliation motives, a significant cluster effect exists $(F(2,507)=9.24, p<0.001)$ : participants of cluster 1 $(M=0.47)$ and cluster $3(M=0.45)$ report significantly higher frequencies than those of cluster $2(M=0.30)$. Achievement motives do not differ between clusters, but show a significant setting effect $(F(11,507)=2.63, p<0.01)$. This motive class is most frequently activated in setting $2(M=0.24), 6(M=0.26)$ and $8(M=0.24)$; significantly more often than in setting $1(M=0.14)$, setting $4(M=0.13)$, setting $7(M=0.08)$, setting $9(M=0.09)$, setting $10(M=0.13)$, setting $11(M=0.09)$ and setting $12(M=0.12)$. Only setting 3 $(M=0.17)$ and setting $5(M=0.15)$ are of medium range and do not show any significant differences. For power motives, sentience motives, and higher order motives, no significant differences in relative frequency exist.

Well-being. For physical comfort motives no significant differences between settings or clusters can be found. For power motives, only cluster differences are found $(F(2,329)=4.48, p<0.05)$. Cluster $3(M=0.002)$ shows significantly better wellbeing than cluster $1(M=-0.24)$ and cluster $2(M=-0.44)$. For affiliation motives, only cluster differences are present $(F(2,260)=12.88, p<0.001)$ in the usual pattern. For sentience motives, only cluster differences in the usual pattern can be found $(F(2$, $355)=4.10, p<0.05)$. For achievement motives, well-being can only be analysed for three settings $\quad(5,6$ and 8$)$. Only cluster effects $(F(2,108)=5.06, p<0.01)$ exist. Well-being within higher order motive activation shows only the cluster effect $(F(2,292)=11.67$, $p<0.001)$ being significant. Table 6 gives a description of relative frequency and well-being. 
Table 6. Relative frequency of motive activation and respective well-being by cluster

\begin{tabular}{|c|c|c|c|c|c|c|c|c|c|c|c|c|c|c|c|c|c|}
\hline & \multicolumn{8}{|c|}{ Relative frequency } & \multicolumn{8}{|c|}{ Well-being } & \multirow[t]{3}{*}{ Settings analysed } \\
\hline & \multicolumn{2}{|c|}{ Cluster 1} & \multicolumn{2}{|c|}{ Cluster 2} & \multicolumn{2}{|c|}{ Cluster 3} & \multicolumn{2}{|c|}{ Total } & \multicolumn{2}{|c|}{ Cluster 1} & \multicolumn{2}{|c|}{ Cluster 2} & \multicolumn{2}{|c|}{ Cluster 3} & \multicolumn{2}{|c|}{ Total } & \\
\hline & $M$ & $(\mathrm{SD})$ & $M$ & (SD) & $M$ & (SD) & $M$ & $(\mathrm{SD})$ & $M$ & $(\mathrm{SD})$ & $M$ & $(\mathrm{SD})$ & $M$ & $(\mathrm{SD})$ & $M$ & $(\mathrm{SD})$ & \\
\hline Physical comfort motives & 0.19 & $(0.31)$ & 0.24 & $(0.34)$ & 0.13 & $(0.26)$ & 0.18 & $(0.30)$ & -0.31 & $(0.95)$ & -0.22 & $(1.04)$ & 0.00 & $(1.02)$ & -0.18 & $(1.00)$ & $1,4,5,6$ \\
\hline Power motives & 0.50 & $(0.38)$ & 0.51 & $(0.38)$ & 0.45 & $(0.36)$ & 0.48 & $(0.37)$ & -0.24 & $(1.01)$ & -0.43 & $(0.92)$ & 0.00 & $(1.00)$ & -0.19 & $(1.00)$ & $\begin{array}{l}1,2,4,5,6, \\
8,9,10,12\end{array}$ \\
\hline Affiliation motives & 0.47 & $(0.38)$ & 0.30 & $(0.31)$ & 0.45 & $(0.35)$ & 0.42 & $(0.36)$ & -0.05 & $(0.81)$ & -0.38 & $(0.84)$ & 0.27 & $(0.88)$ & 0.01 & $(0.88)$ & $\begin{array}{l}1,4,5,6,8 \\
10,12\end{array}$ \\
\hline Sentience motives & 0.67 & $(0.34)$ & 0.62 & $(0.36)$ & 0.63 & $(0.34)$ & 0.64 & $(0.34)$ & -0.19 & $(0.83)$ & -0.20 & $(0.93)$ & 0.11 & $(0.98)$ & -0.07 & $(0.93)$ & $\begin{array}{l}1,2,4,5,6,8 \\
10,11,12\end{array}$ \\
\hline Achievement motives & 0.18 & $(0.29)$ & 0.14 & $(0.25)$ & 0.15 & $(0.23)$ & 0.16 & $(0.26)$ & 0.19 & $(0.67)$ & -0.18 & $(0.79)$ & 0.28 & $(0.75)$ & 0.13 & $(0.75)$ & $5,6,8$ \\
\hline Higher order motives & 0.44 & $(0.36)$ & 0.48 & $(0.36)$ & 0.51 & $(0.38)$ & 0.48 & $(0.37)$ & 0.08 & $(0.70)$ & -0.18 & $(0.80)$ & 0.34 & $(0.83)$ & 0.12 & $(0.80)$ & $\begin{array}{l}1,4,5,6,8 \\
9,10,12\end{array}$ \\
\hline
\end{tabular}

Mean $(M)$, standard deviation (SD); settings were analysed if all clusters showed more than five observations. 


\section{DISCUSSION}

Through the method of the time sampling diary, this study has examined the affective condition experienced over 2 weeks by 74 drug addicts entering treatment at residential Communities based on a non-behaviourist therapy model.

The results of the analyses performed on the drug-related characteristics of these subjects show that they do not form a homogeneous group but are differentiated according to three specific aspects: failures in previous treatment vs. absence of previous treatment, duration of drug addiction, presence vs. absence of prison experience.

We will now make a more detailed examination of the mood of the subjects as it emerges from the survey carried out. Over the 2 weeks of observation the individuals as a whole more often experienced emotions with a positive value (optimism, anticipation, acceptance, joy) and report a moderately high average level of well-being. Therefore they appear to be considerably enthusiastic about the experience they have recently embarked on and trust in a positive development. Though the need for sentience is the most frequently referred to in comparison with those of physical comfort and achievement which are certainly the least, the level of well-being experienced is at its most especially when the subjects feel the need for success and high order. While the need for sentience seems to us to be related in some way with the drug history of the subjects and in particular with a focus on the action and on varied experiences, the need for success is instead more linked with the task that the subjects are currently facing and which is found to be an important source of well-being if it is mentioned.

In relation to the degree of variation of the moods of the subjects according to the different settings in which their daily life currently revolves, the main results show that some are evoked more frequently than others. For example setting 6 - being with other participants in a work activity - and setting 5 - being with other participants in leisure time activities - are the most frequently mentioned by the subjects with respect to others such as being at work alone (3), being in therapy sessions with the staff (9), or with people outside the Community (11) which are the least mentioned. While it is plausible that the most frequently mentioned settings are in fact those which take up most of the day of the subjects, it is also possible that for certain aspects they coincide with the most enjoyed and least problematic which in both cases appear to be linked with interaction with the peer group.

However it should be said that the mood of the subjects surprisingly does not vary in relation to the 12 different types of situation which characterise daily life in that context. The exception is only the need for achievement which is activated more frequently, both when the individuals are alone in a moment of pause in the living room (setting 2), in other words when they can freely think and reflect on the experience in progress, and when they find themselves with the staff at work in a community room (setting 8) and are thus involved in achieving a concrete task. The low impact of the setting on the emotional state of the subjects may be related to the experience of novelty stimulated by staying in the Community. The new environment is fully accepted, without initially recognizing the distinct characteristics of the situations experienced (work, free time, therapeutic activities). It is foreseeable that this initial state of absolute euphoria will be modified later so that the experience of the subjects will become more differentiated making them able to respond in a way coherent with the 'informative' inputs from their current living environment. An alternative interpretation would be that the sample of persons studied is for some aspects not very sensitive to variation of situations. On the basis of our direct observations we can 
exclude the suggestion that the situations (settings) within the Community are rather uniform in their stimulation characteristics.

Instead, mood varies considerably in relation to the diversified background experiences of the subjects. More specifically, the subjects of cluster 1, with a long history of addiction, experiences of imprisonment and previous failures, show emotions of anger and remorse less frequently than the other groups and anticipation more often than cluster 3 and show a medium level of well-being. They more often mention the need for physical comfort in comparison with cluster 3 and the need for affiliation in comparison with cluster 2 and they feel the needs of achievement to be particularly satisfied. The subjects of cluster $2-$ long history of addiction, experiences of imprisonment, absence of previous treatment - more often appear disgusted and less frequently surprised with respect to the other groups and they more often mention emotions of anticipation in comparison with cluster 3 . They show the lowest level of well-being and consider most of their needs to be particularly unsatisfied (power, affiliation, sentience, achievement and higher order). Unlike the subjects of these groups, those of cluster 3 - short history of addiction, no experience of imprisonment and failure - mention ambivalent emotions with more frequency (joy, optimism, love vs. aggressiveness), they show the highest levels of well-being and, like the subjects of cluster 1, refer to needs of affiliation with more frequency. In addition, they consider the needs of high order, of achievement, of affiliation and of power to be particularly satisfied. These are subjects who attribute the cause of their well-being more frequently to external factors but they also show the highest levels of well-being both in internal and external attributions. In short, it could be said that while the subjects of clusters 1 and 2 more often mention emotions linked to the expectation of something which is still uncertain and undetermined, those of cluster 3 , by mentioning both some positive emotions and some negative, show more ambivalent emotions. In addition, while the former feel satisfied at least as regards success, the latter appear unsatisfied as regards all needs, unlike the subjects of cluster 3 who instead consider the majority of their needs to be satisfied.

It would seem therefore that a long drug history and experiences of imprisonment (clusters 1 and 2) are associated with lower levels of well-being in coping with the new aspects of life in the Community, and that this experience is felt particularly by the subjects of cluster 2 in negative continuity with that of the present time. The fact of having had previous failures in other Communities (cluster 1) does not seem to accentuate the feelings of failure but on the contrary to foster a certain level of well-being. The impact with Community life appears overall to be worst in the case of the subjects of cluster 2 . The condition of considerable enthusiasm expressed by the subjects of cluster 3 , which however is accompanied by a certain ambivalence (both in terms of emotions felt, and of attributions about their own emotional state) may perhaps be the effect of the overall novelty of the particular social situation of the Community. Besides, the fact that the beginning of the transition is associated with low levels of well-being especially for the subjects of cluster 2 is presumably an indication of the fact that it is approached with a certain degree of anxiety and/or with feelings of threat. This could reduce the resorting to strategies of active coping, making the definition of objectives of change more unlikely but not excluding it completely. The higher levels of well-being expressed by the subjects of cluster 3 , increasing the feelings of trust and control, appear to be more able to promote the search for new forms of adaptation or different forms of personal equilibrium.

Because the results of this survey show that the emotional states of drug addicts at the beginning of treatment differ greatly according to their drug history, it seems to us to imply 
as regards the interventions of rehabilitation that in order to reduce possible drop-out phenomena it is necessary to reduce as far as possible the states of distress experienced by those with experiences of imprisonment and a long drug history.

The mood sampling diary has provided valuable insights into the first 2 weeks of treatment. Follow up studies over the process of rehabilitation could provide a more comprehensive picture of the effects of treatment within this type of residential communities.

\section{REFERENCES}

Alcoholics Anonymous 1955. The Story of How Many Thousands of Men and Women Recovered from Alcoholism. Alcoholics Anonymous World Service: New York.

Alexander BK. 1990. The empirical and theoretical bases for an adaptive model of addiction. Journal of Drug Issues 17: 57-66.

Alexander BK, Hadaway PF. 1982. Opiate addiction: the case for an adaptive orientation. Psychological Bulletin 2: 367-381.

Baumrind D, Moselle KA. 1985. A developmental perspective on adolescent drug use. Advances in Alcohol and Substance Use 5: 51-55.

Becker H. 1953. Becoming a marijuana user. American Journal of Sociology 59: 235-242.

Becker P. 1991. Theoretische grundlagen. In Wohlbefinden: Theorie, Empirie, Diagnostik, Abele A, Becker P (eds). Juventa: Weinheim; 13-50.

Berger PL, Luckman T. 1966. The Social Construction of Reality. Doubleday: New York.

Bettelheim B. 1960. The Informed Heart. Free Press: New York.

Biernacki P. 1986. Pathways from Heroin Addiction: Recovery without Treatment. Temple University Press: Philadelphia.

Brandstätter H. 1977. Wohlbefinden und Unbehagen. Entwurf eines Verfahrens zur Messung situationsabhängiger Stimmungen. In Bericht über den 30: Kongreß der DGfPS in Regensburg 1976, Band 2, Tack WH (ed.). Hogrefe: Göttingen; 60-62.

Brandstätter H. 1983. Emotional responses to other persons in everyday life situations. Journal of Personality and Social Psychology 45: 871-883.

Breckler SJ, Greenwald AG. 1986. Motivational facets of self. In Handbook of Motivation and Cognitio: Foundations of Social Behavior, Vol. I, Higgins ET, Sorrentino RM (eds). Guilford: New York; $145-161$.

Cagossi M. 1988. Comunità terapeutiche e non. Borla: Rome.

Carman RS. 1979. Motivations for drug use and problematic outcomes among rural junior high school students. Addictive Behaviors 4: 91-93.

Clore GL. 1992. Cognitive phenomenology: feelings and the construction of judgment. In The Construction of Social Judgment, Martin LL, Tesser A (eds). Erlbaum: Hillsdale, NJ; 133-164.

Finazzi L. 1996. Alla ricerca del sé perduto. Edizioni Dehoniane: Bologna.

Gendlin E. 1964. A theory of personality change. In Personality, Change, Worchel P, Byrne D (eds). Wiley: Chicago; 100-148.

Goffman E. 1961. Asylum: Essays on the Social Situation of Mental Patients and Other Inmates. Doubleday: New York.

Hormuth SE. 1986. The sampling of experiences in situ. Journal of Personality 54: 262-293.

Jacobsen E. 1957. Normal and pathological moods: their nature and function. In The Psychoanalytic Study of the Child, Eisler RS, Freud AF, Hartman H, Kris E (eds). International University Press: New York; 73-113.

Kennard D. 1983. An Introduction to Therapeutic Community. Routledge \& Kagan: London.

Kirchler E. 1983. Lo stato d'animo in una caserma militare. Psicologia e Lavoro 57/58: 128-183.

Kirchler E. 1984. Befinden von Wehrpflichtigen in Abhängigkeit von personellen und situativen Gegebenheiten. Psychologie und Praxis. Zeitschrift für Arbeits- und Organisationspsychologie 28: $16-25$.

Lewinson PM, Libet J. 1972. Pleasant events, activity schedules, and depressions. Journal of Abnormal Psychology 79: 291-295. 
Miller WR. 1983. Motivational interviewing with problem drinkers. Behavioural Psychotherapy 11: 74-86.

Ministero dell'Interno-Direzione generale per l'Amministrazione Generale e per gli Affari del Personale. 1996. Tossicodipendenti in trattamento presso i Servizi sanitari pubblici e le strutture socio-riabilitative alle date del 31 Marzo e 30 Giugno 1996. Analisi dei casi di decesso per assunzioni di stupefacenti, I semestre.

Monti PM, Abrams DB, Kadden RM, Cooney NL. 1989. Treating Alcohol Dependence. Cassel: London.

Nowlis V, Nowlis HH. 1956. The description and analysis of mood. Annals of the New York Academy of Sciences 65: 345-355.

O'Doherty F, Davies JB. 1987. Life events and addiction: a critical review. British Journal of Addiction 82: 127-137.

Palmonari A (ed.). 1997. Psicologia dell'adolescenza. Il Mulino: Bologna.

Plutchik R. 1980. Emotion: A Psychoevolutionary Analysis. Harper \& Row: New York.

Prochaska JO, Di Clemente C. 1986. Toward a comprehensive model of change. In Treating Addictive Behaviors, Miller WR, Heather N (eds). Plenum Press: New York; 3-27.

Ravenna M. 1991. Le Comunità per tossicodipendendenti. In Comunità di convivenza e crescita della persona, Palmonari A (ed.). Patron: Bologna; 108-199.

Ravenna M. 1993. Adolescenti e droga. Il Mulino: Bologna.

Ravenna M. 1995. La dipendenza e l'interruzione deòl rapporto con la droga. In Le dimensioni della Psicologia Sociale, Zani B (ed.). La Nuova Italia Scientifica: Rome; 401-432.

Ravenna M. 1997. Psicologia delle tossicodipendenze. Il Mulino: Bologna.

Ravenna M, Zani B. 1996. Strategie di coping e aspetti del Sé in un campione di tossicodipendenti. Bollettino di Psicologia Applicata 220: 41-50.

Ravenna M, Palmonari A, Scappini E. 1997. Rappresentazioni di Sé in diverse fasi di remissione della tossicodipendenza. Psicologia Clinica dello Sviluppo 1(1): 63-93.

Ravenna M, Kirchler E. 2000. Giovani e tempo del loisir. Ricerca di eccitazione, percezione del rischio e rappresentazioni del giorno e della notte. Giornale Italiano di Psicologia 3: 573-604.

Redl F, Wineman D. 1951. Children Who Hate. Free Press: New York.

Ruble DN, Seidman E. 1996. Social transitions: windows into social psychological processes. In Social Psychology: Handbook of Basic Principles, Higgins ET, Kruglanski AW (eds). Guilford Press: New York; 830-856.

Singer JL, Kolligian Jr J. 1987. Personality: developments in the study of private experience. Annual Review of Psychology 38: 533-574.

Van Bilsen H, Van Emst A. 1990. Motivating heroin users for change. In Treating Drug Abusers, Bennett G (ed.). London: Routledge: London; 29-47.

Waldorf D. 1983. Natural recovery from opiate addiction. Some social psychological processes on untreated recovery. Journal of Drug Issues 13: 257-280. 